\title{
The Learning Path of the Hidden Economy: the Tax Burden and Tax Evasion in New Zealand
}

\author{
David E. A. Giles \\ Department of Economics \\ University of Victoria \\ Victoria, B.C. \\ CANADA
}

and

Patrick J. Caragata

McCallum Petterson Diagnostics

P.O. Box 3156

Wellington

NEW ZEALAND

Revised, May 1999

\begin{abstract}
This paper considers the "learning curve" relationship between the aggregate tax rate and the relative size of the hidden economy in New Zealand. Some simple non-linear models are estimated so that the effects of changes in the effective tax rate on the underground economy can be simulated. We find that about half of the hidden activity in New Zealand is a learned response to changing opportunities and constraints in fiscal policy, but this amount varies over the business cycle. Simulating a zero tax rate permits us to discover the "natural rate" of underground and criminal activity. Some partial lessons are drawn for taxation policy in that country.
\end{abstract}

Key Words: Taxation, Underground Economy, Effective Tax Rate

JEL Classification Numbers: $\quad$ C22, H21, H26

Correspondence: $\quad$ Professor David Giles, Department of Economics, University of Victoria, P.O.

Box 1700, STN CSC, Victoria, B.C., CANADA V8W 2Y2

FAX: +1-250-721 6214 Voice: +1-250-721 8540 e-mail: dgiles@uvic.ca 


\section{INTRODUCTION}

This paper deals with the hidden economy in New Zealand, and the extent to which its relative size can be affected by changes in the aggregate (effective) tax rate. This is an important issue, for several reasons. Activity in the hidden economy poses a serious threat to both fiscal and monetary policy, as well as to respect for the law. As the relative size of the hidden economy grows, so does financial activity which is beyond the control of the central bank, and the potential for political corruption. The associated growth of tax evasion leads to an increasing degree of cynicism about the role and power of government, and about the effectiveness of the tax system. It also reduces public support for the philosophy of "voluntary compliance" - the basis for the stability of the tax system in many democratic societies (e.g., Clotfelter, 1983).

There has been a recent resurgence of interest in the hidden economy on the part of both researchers and policy-makers in many countries. For example, see Rahman (1992), Caragata (1995), and the numerous references cited by Giles (1999b). Among other things, unpaid tax in the hidden economy, or loopholes allowing abusive avoidance in the existing tax system, create a deadweight (allocative efficiency) loss on the economy (Harberger, 1964), and also undermine taxation equity by shifting the burden in the direction of honest, socially responsible, individuals and corporations. Further, a growing hidden economy gives rise to an increasing segment of the money supply which is uncontrolled, and thus undermines inflation policy. Any increase in the rate of inflation can also result in a significant long-term deadweight loss (Feldstein,1996).

In summary, a growing hidden economy may reflect, among other things, inefficient tax policy, an inefficient formal banking sector and inefficient monetary policy, with potentially serious adverse implications for future economic growth and for public confidence in government. So, it is important to have a proper understanding of the incentive structure that drives the behaviour that shapes the temporal development of the hidden economy.

The incentive to avoid and evade taxes in response to an increasing tax burden has been longrecognised. For example, Taussig (1925, p.528) noted: "...not a little depends, to be sure, on the amount of the tax. The higher it becomes, the greater is the danger of evasion, [and] the greater is the difficulty of preventing demoralization." Intuitively, the level of the tax rate is linked to the 
security of the tax base: the higher are taxes, the greater is the risk to the base (if one is an optimist), or the smaller is the base (if one is a pessimist). Among the important issues which then arise are the determination of the tax rate at which the propensity to evade or avoid begins to accelerate; and the "threshold" level of underground activity that may prevail, even in the absence of any taxes, at different points in the business cycle. Such measurements require quantitative information about the size of the hidden economy. Often, reliable such data are difficult to obtain, but in the New Zealand context an annual time-series is available from the extensive work reported by Giles (1999b).

In this study we estimate some simple, partial, relationships between the ratio of hidden to measured GDP (H/GDP) and the ratio of total tax revenue to GDP (T/GDP) in New Zealand. Our objective is to measure the aggregate response of (relative) underground activity to changes in the overall "tax burden", as measured by the aggregate effective tax rate. For reasons detailed below, we expect that an increase in the tax burden will lead to an increase in underground activity, ceteris paribus. The precise form of this positive response path is interesting, and it provides a basis for computing the elasticity between the above two ratios.

We are particularly concerned with determining the likely "threshold" size of the hidden economy - that is, the extent to which underground activity will take place even in the absence of taxation. This threshold is important in terms of distinguishing between tax-driven activity and organised criminal activity in the hidden economy which has motivations other than tax evasion. This in turn assists in evaluating the extent to which the "tax-gap"can be bridged by means of fiscal policy, as opposed to the use of legislation which is directed towards reducing criminal activity. We are also interested in measuring the upper limit of hidden activity as the (T/GDP) ratio is varied, and with determining the value of the tax burden which maximizes the rate of response in the (H/GDP) ratio.

Of course, we recognise that fiscal policy generally has multiple objectives, and variations in the tax rate are undertaken for various reasons, and not just to impact on tax evasion. So, for example, the effective tax rate that is optimal in terms of the response of underground output and tax evasion, may not be optimal in terms of maximizing the growth of measured output in the economy. We also recognise that there are many causes of (measured) economic growth, such as initial endowments, technological changes, and the institutional framework, and that significant 
developments have taken place in recent years in economic growth theory. This is typified by the “endogenous growth" literature spawned by Romer (1986) and Lucas (1988), and summarised by Barro and Sala-i-Martin (1995). In this paper we are not concerned with the growth of the underground economy, as such, but simply with the broad nature of the linkage between the relative size of the hidden sector of the economy and the relative tax burden.

In the following analysis we focus entirely on the aggregate tax burden, and our use of the actual aggregate historical tax data implies that our results hold under the (varying) tax-mix that held over our sample period. The implications of varying the tax-mix (as between personal, corporate, indirect, and other tax components) for the size of the hidden economy are also of interest, and these are considered ${ }^{1}$ by Caragata and Giles (1998). In fact, in relation to the above discussion, they show that there is a very close accordance between the "growth maximizing" tax rate found by Scully (1996) and the optimal rate in respect of a tax evasion objective. In the next section we discuss some aspects of the link between taxes and the hidden economy. Section III describes the basic methodology for our investigation, and section IV reports the empirical results. Some economic implications are discussed in section $\mathrm{V}$, and section VI provides our conclusions.

\section{TAXES AND A LEARNING CURVE FOR UNDERGROUND ACTIVITY ${ }^{2}$}

The theory of the formation of incentive structures provides insights into the stimulus-response link between tax shocks created by government and subsequent behavioural responses by firms and individuals. In particular, the interaction between the tax-shock stimulus, combined with the learned response to opportunities and constraints, affects the size of the hidden economy and the tax-gap.

The stimulus-response link shapes the associated learning curve. In general, the incremental theory of learning specifies that "learning increases gradually as a result of reinforced practice" (Houston, 1976, p.131). Practice is reinforced because of the presence of opportunities, constraints (which contain costs and penalties) and rewards. The learning curve is an evolutionary depiction of the behavioural consequences of the incentive structure operating in a particular jurisdiction or organisation. Taxes are a current and potential cost of doing business

for firms, and a current and potential cost of living for individuals. Just as taxes reduce cash flow 
for firms, they also reduce disposable income for individuals. Consequently, together with other important factors, taxes affect the incentive structures of both firms and individuals.

Because taxes have a current and potential impact on a firm cash flow, they may affect the immediate choices that firms make with respect to the purchase of inputs, the avoidance or evasion of taxes, the production of outputs, and undertaking new investments, etc. For individuals, taxes are a cost of living. Their choices concern the decisions to purchase items in the consumption basket, and to avoid or evade taxes by not reporting income or purchases.

Opportunities to disguise income are apparently pro-cyclical (Giles, 1997a, 1997c, 1999a), gaining strength with each business upturn, and they depend on the use of cash in transactions (Giles, 1999b) and the ability to shield information from the revenue authorities. The degree of compliance by individual taxpayers is also a matter of learned behaviour that responds to various constraints. There is general agreement that compliance rises with the increase in the pressures which shape deterrence (e.g., Klepper and Nagin, 1989).

However, tax evasion is a learned process that is shaped simultaneously by the cost savings in the opportunities to evade and the constraints and related penalties against such illegal activity. Thus, evasion opportunities are continually being shaped at finer levels of detail by the coefficient between perceived reward and probability-adjusted risk. Klepper and Nagin (1989, p.23) have captured this pursuit of detail in the search for risk-minimising evasion opportunities, in their study of 50,000 taxpayer returns in the United States in 1982: "...our findings suggest that compliance behaviour conforms closely to the incentives and deterrents created by the enforcement environment. We find marked variations in compliance levels across line items which appear to be systematically related to the difficulty of establishing noncompliance and the penalties for detected noncompliance. We also find that the influence of the endogeneity of detection risk and penalties is pervasive. Ex ante, taxpayers appear to allocate their noncompliance across line items to minimise expected penalties. They avoid extreme noncompliance on specific line items and appear to recognize the influence of noncompliance on one line item (or set of line items) on the risk of detection of noncompliance on other line items". 
In the modern "endogenous growth" literature, some authors have found that taxes are of limited importance in explaining differences in growth rates (e.g., Levine and Renelt, 1992, Easterly and Rebelo, 1993, and Sala-i-Martin, 1995). However, using a different methodology, Scully (1995, 1996) found a negative relationship between taxes and output growth, and he explored the notion of a "growth maximizing" tax rate. In the case of "hidden" output it seems clear that there is a relationship between the opportunity to hide income and the ability and willingness to evade taxes by participating in the underground economy. This is borne out both by theoretical economic models and by the limited available empirical evidence. With regard to the latter, Gutmann (1977, p.5) suggests that "higher and higher taxes drive more and more of the economy underground, beyond the reach of the tax collector". Slemrod (1985, p.237) found that high marginal effective tax rates promote evasion, although there is no evidence that higher income earners engage in tax evasion more than lower income earners. Using Canadian survey data , Lemieux et al. (1994) estimated a micro-model that accounts for nonlinearities in the tax-andtransfer system, and found a positive relationship between the tax rate and the probability of underground activity. In the New Zealand context, Giles (1999b) found that average-average and average-marginal tax rates; the ratios of corporate tax to GDP and of other persons' taxes to GDP; and an index of the intensity of taxation legislation, are all highly important determinants of the size of the hidden economy in his latent variable structural model ${ }^{3}$.

There are also some clear theoretical underpinnings for these (and other related) findings. Several authors have studied the theoretical relationship between tax rates and tax evasion, but much of this analysis relates only to "pure tax evasion" models (in the spirit of Allingham and Sandmo,1972), in which income is earned from only one source. In addition, it is often unrealistically assumed that any penalties are imposed on undeclared income (rather than on evaded tax). Of more relevance are the more recent contributions (e.g., Kesselman, 1997 and others) relating to two-sector "underground economy" models, in which an agent's income source affects the probability that tax evasion will be detected. In this context, the assumptions that are made regarding agents' risk-aversion can be crucial. The theoretical results that are most relevant to our own investigation are those developed by Trandel and Snow (1999). They show, inter alia, that if taxes are progressive and if agents' preferences exhibit decreasing absolute and nondecreasing relative risk aversion, then an increase in the tax rate leads to increased tax evasion. 
While there is justification for exploring the link between taxes and the underground economy, it is also clear that the latter has many other determinants ${ }^{4}$. However, our task here is simply to investigate some simple partial relationships between the aggregate tax rate and the relative size of the underground economy, and to explore this relationship as an example of a learning curve on the part of tax-paying agents.

\section{METHODOLOGY}

We have considered a wide range of simple functional relationships between (H/GDP) and (T/GDP). The latter aggregate ratio was not one of the causal variables adopted in the latent variable modelling that was used to construct the former series in Giles (1999b), so the estimation of such relationships is not a redundant exercise. In each case, the proportional rate of growth in real GDP $\left(\Delta\right.$ GDPR/GDPR $\left._{-1}\right)$ is included as a second explanatory variable ${ }^{5}$, in view of the highly cyclical nature of the (H/GDP) ratio. After some unsuccessful experimentation with simple polynomial relationships (see also Scully, 1996), and a Fourier approximation, we have concentrated on functional forms which allow for a non-linear relationship between (H/GDP) and (T/GDP); which have a single point of inflection; and which allow for the possibility of positive "saturation" and "threshold" levels in the dependent variable ${ }^{6}$. The principal functional forms that we have explored are.

\section{Cumulative Normal}

$$
\left.(\mathrm{H} / \mathrm{GDP})=\Phi[((\mathrm{T} / \mathrm{GDP})-\alpha) / \beta]+\left(\Delta \mathrm{GDPR}_{\mathrm{GDPR}}\right)_{1}\right)+ \text { error },
$$

where $\Phi($.$) is the cumulative standard Normal distribution function.$

\section{Logistic}

$(\mathrm{H} / \mathrm{GDP})=1 /[1+\exp \{-((\mathrm{T} / \mathrm{GDP})-\alpha) / \beta\}]+\left(\Delta \mathrm{GDPR} \mathrm{GDPR}_{-1}\right)+$ error.

\section{Gompertz}

$(\mathrm{H} / \mathrm{GDP})=\alpha^{\mathrm{f}(\mathrm{T} / \mathrm{GDP})}+\gamma\left(\Delta \mathrm{GDPR} / \mathrm{GDPR}_{-1}\right)+$ error, where $f(T / G D P)=\beta^{(T / G D P)}$. 


\section{Extreme-value}

$$
(\mathrm{H} / \mathrm{GDP})=1-\exp \{-\exp [((\mathrm{T} / \mathrm{GDP})-\alpha) / \beta]\}+\left(\Delta \mathrm{GDP}_{\mathrm{GDP}}-1\right)+\text { error } .
$$

\section{ECONOMETRIC RESULTS}

Annual data for the (H/GDP) variable are available for the period 1968 to 1994 from the results of Giles (1999b). The annual data for Total Tax Revenue (T) are on a Budget (rather than Inland Revenue Department) basis, and are from Colgate (1991), with post-1990 data having being compiled by New Zealand Inland Revenue Department and Treasury staff. Nominal GDP includes a stock valuation adjustment, and this series is an extended version of that reported by Colgate (1991), with the latest official revisions incorporated into the series. The data for (H/GDP) and for (T/GDP) are plotted in Figure 1, and are available at

\section{http://www.uvic.ca/econ/uedata.html.}

As we are dealing with annual time-series data, it is important to test whether or not the various series are stationary, so that we will avoid fitting "spurious regressions" (e.g., Granger and Newbold, 1974). If the data are found to contain unit roots, then the possibility of cointegration between the variables also needs to be examined, as this determines the appropriate form in which the variables should enter the model. For example, if the series are integrated of order one (i.e., I(1)), but are not cointegrated, then the series should be first-differenced prior to use. If they are I(1) and are also cointegrated, then we may either fit a long-run cointegrating relationship using the levels of the (non-stationary) data, or we can fit an error-correction model which involves using the differenced data and the lagged residuals from the cointegrating regression to construct a model which captures short-run dynamics.

The results of testing for unit roots in the time-series for the hidden economy/measured GDP ratio, (H/GDP), the total tax revenue/GDP ratio, (T/GDP), and the rate of growth in real GDP appear in Table 1(a). The (net) sample size is denoted "n", and in the Augmented Dickey-Fuller (ADF) test the augmentation level is denoted " $p "$, and " $t$ " is the "t-statistic" for the case where the ADF regression includes a drift and linear trend. The results were obtained by using the "COINT" command in the SHAZAM (1997) econometrics package. Dods and Giles (1995) 
provide Monte Carlo evidence which supports the use of the default SHAZAM method for determining the augmentation level in samples of the size used here.

The null hypothesis for the ADF test is non-stationarity, and the alternative hypothesis is that the series is stationary. Given the well-known low power of the ADF test, we have also applied the test of Kwiatowski et al. (1992) (the "KPSS" test). In this case the null hypothesis is stationarity, and the alternative is that the series has a unit root. For both tests, we report results relating only to the trend-stationary case, rather than the level-stationary case, but the this does not affect our overall conclusions. For the KPSS test, " $l$ " is the truncation lag parameter ${ }^{7}$ for the spectral window, and is the (locally best invariant) Lagrange Multiplier statistic.

We see that of the three series, the rate of growth in real GDP is (trend) stationary, which is consistent with the logarithm of real GDP itself being I(1). The other two ratio variables are both I(1). These results are sensible in relation to the other available international empirical evidence ${ }^{8}$. Given the non-stationarity of the aggregate tax rate and the hidden/measured GDP series, we have tested for possible cointegration between them, using the Engle-Granger (1987) two-step procedure. The results, based on both ADF and KPSS tests, appear in Table 1(b). The notation is as above, except, of course that " $t$ " now denotes the ADF "t-statistic" with no drift and no trend in the ADF regression, and for this test the "drift/no trend" and "drift \& trend" headings in Table 1(b) refer to the specification of the associated "cointegrating regressions". For the KPSS test, the " $\eta_{\mu}$ " and " $\eta_{\tau}$ " statistics relate to the "level stationary" and "trend stationary" cases. From both the ADF and KPSS results, there is clear evidence that (H/GDP) and (T/GDP) are cointegrated, so the models discussed in the last section are estimated using the actual values (rather than the first-differences) of the data. As we are interested in long-run relationships, rather than in shortrun dynamics, we do not consider the estimation of error-correction models here ${ }^{9}$.

Among the various functional relationships that have been considered, the four that were detailed in the last section produced the most promising results. These models were estimated by nonlinear Maximum Likelihood with the SHAZAM econometrics package, and the results appear in Table 2. In that table, asymptotic "t-values" appear in parentheses; $\mathrm{R}^{2}$ is the squared correlation between the actual and "fitted" values; GOF is the "goodness of fit" test for Normality (and is 
asymptotically Chi Square with two degrees of freedom); and DW is the exact Durbin-Watson statistic, computed for these non-linear models in the manner proposed by White (1992).

Clearly, there is very little difference between the statistical results for the different specifications. ${ }^{10}$ The estimated coefficients are generally quite significant, the errors are normally distributed, and the residuals are free of autocorrelation (at least at the $1 \%$ significance level). Attempts to re-estimate the models with an explicit allowance for possible autocorrelation resulted in fitted relationships which were totally implausible in economic terms.

Table 3 shows the results of simulating each of the above models with (T/GDP) ratios set at various values. Note that all of the figures in that table are expressed as percentages. Asymptotic standard errors for the simulated (H/GDP) ratios are also presented - these were generated by means of the "ANALYZ" command in the TSP econometrics package (Hall, 1996). In these simulations, the rate of growth of real GDP is set to zero, although in the last row(s) we have simulated the 1994 situation. In that case, the actual rate of growth in real GDP for that year was included. Giles (1999b) estimates that the actual hidden economy/measured GDP ratio was $11.30 \%$ in 1994 . To check the plausibility of our results, we see that the simulated values for (H/GDP) in that year are all (effectively) within two asymptotic standard errors of that actual figure.

Figure 2(a) plots the simulated time-path from the Logistic model, using the data generated according to the conditions ${ }^{11}$ in Table 3. Figures 2(b) to 2(d) show the associated first and second partial derivatives, and the partial (point) elasticity between (H/GDP) and (T/GDP) when the latter ratio ranges from zero to $100 \%$. Although the curve in Figure 2(a) has a positive second derivative over this full range, it actually has a point of inflection at (T/GDP) $=126.65 \%$ (the estimated value of $\alpha$ for this model in Table 2), and flattens out above this (hypothetical) effective tax rate. This is reflected, of course, in the shape of the curve in Figure 2(c), where the second derivative of the relationship is maximized at a tax rate of about $70 \%$, and falls to zero at a tax rate of $126.65 \%$. 


\section{ECONOMIC IMPLICATIONS}

The econometric result, in Table 1(b), that the (T/GDP) ratio and the (H/GDP) ratio are cointegrated, has important economic implications. First, it implies that there is a long-run equilibrating relationship between these two important ratios - any exogenous shock to the system is eventually absorbed, and the two variables cannot "drift apart" in the long run. This is consistent with the time-path shown in Figure 1. Moreover, the presence of cointegration implies the existence of (Granger) causality between (T/GDP) and (H/GDP), in one direction or both. The details of this causality are not discussed in this paper. However, we have formal evidence already (based on a consistent set of New Zealand data) from Scully (1996), relating to the causal link from taxes to measured output growth; and from Giles (1997a) relating to the causality from the measured economy to the hidden economy. Our finding of a cointegrating relationship here supports the presence of causality between the tax burden and the relative size of the hidden economy.

Regardless of the specific functional form that is chosen, the results in Table 3 suggest that (with a zero growth rate in real GDP, and a zero "tax burden"), the minimum "threshold" value for the size of the hidden economy is approximately $4 \%$ to $4.5 \%$ of measured output. This compares reasonably with the long-run average value of $8.8 \%$ for the hidden economy ratio, reported by Giles (1999b). His smallest (estimated) value for the (H/GDP) ratio over our sample period was $6.86 \%$ in 1968, and the largest corresponding value was $11.30 \%$ in 1994 , which equates to NZ\$9.2 billion in that year.

This threshold figure of $4 \%$ to $4.5 \%$ represents the inherent size of the hidden economy that cannot be eliminated purely by means of a totally liberal fiscal policy. It might be described as "the natural rate of underground activity", and can be interpreted as the "hard-core" of the hidden economy that is driven by motives other than tax evasion. Such motives will be essentially valuedriven, and are based on a social or market preference for non-conformist behaviour, or for criminal activity.

Consider the (average) hard-core figure of $4.4 \%$ for the Logistic model (which produces results which are the most plausible in economic terms), for instance. This suggests that, on average 
over the long run, about half of the hidden economy is driven by taxation considerations (constraints with attached costs). The remaining half comprises structural and cyclical opportunities. However, it should be noted that this apportioning of the hidden economy varies markedly over the business cycle. For instance, during a recession, the hard core accounts for considerably more (e.g., 65\%, based on $4.4 \% / 6.8 \%$ in 1968) of the total the hidden economy than during the peak of a boom (e.g., 39\%, based on 4.4\%/11.3\% in 1994). The difference can be explained by higher levels of tax evasion during economic upturns. In addition, even when cyclical effects are taken into account, one might expect that the size of the hard-core component of the hidden economy may exhibit a trend. In the New Zealand context there is anecdotal evidence that this trend may be positive. If this is so, then currently there would be less potential for reducing tax evasion through fiscal policy than our figures here suggest.

The simulated relative size of the underground economy when the nominal tax-take is $100 \%$ of nominal GDP (and when there is no growth in real output), varies from approximately $28 \%$ to $37 \%$ of measured GDP, depending on the functional form of the model. It is $34.4 \%$ for the preferred Logistic specification. However, there are no significant inconsistencies in these results - informal asymptotic confidence intervals, constructed by taking two standard errors on either side of the simulated values, all overlap one another substantially. This last point holds regardless of the value of the (T/GDP) ratio used in the simulations. Given that the current tax/GDP ratio in New Zealand is approximately 35\%, this suggests that any increase in the present aggregate tax burden in New Zealand would lead to an increase in the relative size of the hidden economy, with increased tax evasion and abusive avoidance problems.

As noted above, the results associated with the Logistic model are perhaps the most plausible in economic terms, and Figures 2(c) and 2(d) provide some useful insights. From Figure 2(c), we see that the second derivative of the (partial) relationship between (H/GDP) and (T/GDP) reaches a maximum at an aggregate tax rate of approximately $70 \%$ of GDP. We can loosely interpret this graph as depicting the "acceleration rate" in (H/GDP) for different values of (T/GDP), and this can be linked to our discussion of the learning curve in section II above.

From Figure 2(d) we see that a unit elasticity occurs at a tax rate of approximately $47 \%$ of GDP. As the data for (H/GDP) and for (T/GDP) are expressed in percentage terms, these elasticities 
have to be interpreted with care. For instance, consider the situation in 1994, when (T/GDP) = $34.5 \%$ and $(\mathrm{H} / \mathrm{GDP})=11.3 \%$. For this tax ratio, the elasticity is 0.76 . So, suppose that in 1994 the aggregate tax rate had been $c u t$ by $10 \%$ - that is (T/GDP) had been reduced from $34.5 \%$ to $31.1 \%$. Then according to our results, (H/GDP) would have been reduced by $7.6 \%$ (as opposed to 7.6 percentage points) - that is, it would have fallen from $11.3 \%$ to $10.4 \%$. Similarly, if (T/GDP) had been reduced to $20 \%$ in that year (a reduction of $42 \%$ ), then (H/GDP) would have fallen to $7.7 \%$.

Two caveats are in order here. First, as the elasticities are calculated using the estimated parameters from Table 2, the values plotted in Figure 2(d) (as well as in Figures 2(a)-(c)) represent only point estimates. Interval estimates of the elasticity curve could be obtained by computing asymptotic standard errors, as are reported for the curve in Figure 2(a) in Table 3. Accordingly, the above illustrative arithmetic should be treated with caution. Second, the above calculations implicitly assume that changes in the (T/GDP) ratio are achieved with no change to the tax mix (that prevailed in 1994). From a policy perspective, this is somewhat unrealistic, but details such as this are taken up in the related analysis discussed by Caragata and Giles (1998).

Finally, how do these results compare with the other available evidence? It appears that there is very little previous empirical research involving formal empirical simulations of the effect of a tax cut on the size of the hidden economy or on the associated tax gap. However, using a simple model and U.S. data, Clotfelter (1983, p.368) found that "...for a taxpayer with a combined federal and state marginal tax rate of $0.40(40 \%)$, which is about the average for the sample,....a $10 \%$ decline in this tax rate to 0.36 would result in an expected $5 \%$ to $8 \%$ decline in underreporting". For our sample period, the average-marginal and average-average tax rates have mean values of $35 \%$ and $25 \%$ repectively, and the mean (T/GDP) value is $30 \%$. From Figure $2(\mathrm{~d})$, the elasticity associated with the latter figure is 0.67 . So, reducing the aggregate tax burden from $30 \%$ to $27 \%$ (a $10 \%$ cut) is predicted to reduce the relative size of the hidden economy by $6.7 \%$. Although these calculations are rather simplistic, this result seems to accord quite well with that of Clotfelter, noted above.

In terms of other New Zealand evidence, Caragata and Small (1996) have developed a nonlinear, two-equation, dynamic model to explain the relationships between growth in the measured 
and hidden economies, and the tax burden. Their model predicts that an increase in the tax to GDP ratio will reduce growth in measured real activity, and increase growth in the hidden economy. These effects are found to be stronger, the smaller is the initial tax burden. In the case of the hidden economy, they find that a $20 \%$ tax to GDP ratio, over the period 1968 to 1994, as compared to the actual levels that prevailed, would have resulted in a hidden sector that was $26 \%$ smaller than is suggested by the data of Giles (1999b). This finding accords well with our results here. The sample mean for (H/GDP) over 1968 to 1994 is $8.96 \%$. Reducing this figure by $26 \%$ results in a value of $6.6 \%$, which accords closely (especially when the standard error is taken into account) with the simulated figure of $6.9 \%$ for the Logistic model in Table 3 when (T/GDP) is $20 \%$.

\section{CONCLUDING COMMENTS}

In this paper we have estimated some rather simple aggregate relationships between the size of the underground economy (as a percentage of measured GDP) and the effective tax rate in New Zealand. These relationships are deliberately "partial" in nature, and do not purport to represent structural models which "explain" the relative size of the hidden economy. Indeed, the structural latent variable model which is constructed and estimated by Giles (1999b) serves this role. Moreover, this analysis does not attempt to model the determinants of growth in unmeasured output in New Zealand.

The relationships that we have estimated appear to be quite robust in statistical terms, and very plausible in economic terms. They provide quantitative information about the minimum size of the hidden economy that could be achieved, at least on average over the business cycle, even if the tax burden were totally eliminated. They also provide measures of the elasticity between underground activity and the aggregate tax rate. Finally, they provide a starting point in terms of functional forms for more refined relationships which can allow for the disaggregation of total tax into its major components, and so facilitate an analysis of the effects of changes in the tax mix on the hidden economy. These matters are taken up in detail by Caragata and Giles (1998).

On the basis of the available theoretical and empirical evidence, it is reasonable to conclude that a rising tax burden promotes greater hidden economic activity, and more tax evasion. At some 
point below the current tax/GDP ratio of approximately $35 \%$ in New Zealand, the rate of growth of the underground economy and tax evasion will be minimised. Reducing taxes to zero eliminates about $50 \%$ of the hidden economy, on average, suggesting that hard-core criminal activity (despite its propensity to involve tax evasion) is driven by other motives. The residual soft-core tax evasion, which is evasion not motivated by organised criminal activity, needs to be studied more thoroughly to observe the potential simulated reaction to changes in the tax rate and the tax mix. Finally, it is clear that any policy discussions of changes to both the tax rate and the tax mix need to take into consideration the potential implications for tax evasion behaviour, if the objective is to undertake a comprehensive cost-benefit analysis of changes to tax policy. 


\section{ACKNOWLEDGMENTS}

We thank the following colleagues for their various inputs into the work reported in this paper, either in the form of comments and discussion, or in terms of data assistance: Johannah Branson, Judith Giles, Anna Heiler, Gerald Scully, and John Small. We are also most grateful to Judith Giles for supplying us with SHAZAM code for the KPSS test; and to a referee for several insightful comments and suggestions which enabled us to significantly improve an earlier version of this paper. 


\section{REFERENCES}

Allingham, M. G. and Sandmo, A. (1972) Income tax evasion: A theoretical analysis, Journal of Public Economics, 1, 323-338.

Barro, R. and Sala-i-Martin, X, (1995) Economic Growth, McGraw-Hill, New York.

Caragata, P. J. (1995) The Integration of the Formal and Informal Financial Sectors in Albania, Mission Report for the International Monetary Fund, Washington, D.C..

Caragata, P. J. (1998) The Economic and Compliance Consequences of Taxation: A Report on the Health of the Tax System in New Zealand, Kluwer, Boston, MA.

Caragata, P. J. and Giles, D. E. A. (1998) Simulating the relationship between the hidden economy and the tax level and tax mix in New Zealand, Econometrics Working Paper EWP9804, Department of Economics, University of Victoria, Victoria, B.C..

Caragata, P. J. and Small, P. J. (1996) Monitoring the tax mix, tax shocks and potential economic impacts: The PIC model, Working Paper No. 3a, Working Papers on Monitoring the Health of the Tax System, Inland Revenue Department, Wellington.

Clotfelter, C. T. (1983) Tax evasion and tax rates: An analysis of individual returns, Review of Economics and Statistics, LXV, 363-373.

Colgate, P. (1991) Databases for taxation modelling: Report to the Inland Revenue Department, New Zealand Institute of Economic Research, Wellington.

Dods, J. L. and Giles, D. E. A. (1995) Alternative strategies for 'augmenting' the Dickey-Fuller test: Size-robustness in the face of pre-testing, Journal of Statistical Computation and Simulation, 53, 243-258.

Easterly, W. and Rebelo, S. (1993), Fiscal policy and economic growth, Journal of Monetary Economics, 32, 417-458.

Engle, R. F. and Granger, C. W. J. (1987) Co-integration and error correction: Representation, estimation, and testing, Econometrica, 55, 251-276.

Feldstein, M. (1996) The costs and benefits of going from low inflation to price stability, Working Paper 5459, National Bureau of Economic Research, Cambridge, MA.

Gerrard, W. J. and Godfrey, L. G. (1998) Diagnostic checks for single-equation error-correction and autoregressive distributed lag models, Manchester School, 66, 222-237.

Giles, D. E. A. (1997a), Causality between the measured and underground economies in New Zealand, Applied Economics Letters, 4, 63-67. 
Giles, D. E. A. (1997b), The hidden economy and tax-evasion prosecutions in New Zealand, Applied Economics Letters, 4, 281-285.

Giles, D. E. A. (1997c), Testing for asymmetry in the measured and underground business cycles in New Zealand, Economic Record, 72, 225-232.

Giles, D. E. A. (1999a) The rise and fall of the New Zealand underground economy: Are the responses symmetric?, Applied Economics Letters, 6, 185-189.

Giles, D. E. A. (1999b) Modelling the hidden economy and the tax-gap in New Zealand, Empirical Economics, forthcoming.

Granger, C. W. J. and Newbold, P. (1974) Spurious regressions in econometrics, Journal of Econometrics, 2, 111-120.

Gutmann, P. M. (1977) The subterranean economy, Financial Analysts Journal, 33.

Hall, B. H. (1996) Time Series Processor, Version 4.3 User's Guide, TSP International, Palo Alto, CA.

Harberger, A. C. (1964) Principles of efficiency: The measurement of waste, American Economic Review, 54, 58-76.

Houston, J. P. (1976) Fundamentals of Learning, Academic Press, New York.

Kesselman, J. R. (1989) Income tax evasion: An intersectoral analysis, Journal of Public Economics, 38, 137-182.

Klepper, S. and Nagin, D. (1963) The Shifting of Corporate Income Tax, Johns Hopkins Press Baltimore, MD.

Kwiatowski, D., Phillips, P. C. B., Schmidt, P. and Shin, Y. (1992) Testing the null hypothesis of stationarity against the alternative of a unit root: how sure are we that economic time series have a unit root?, Journal of Econometrics, 54, 159-178.

Lemieux, T, Fortin, B., and Fréchette, P. (1994) The effect of taxes on labor supply in the underground economy, American Economic Review, 84, 231-254.

Levine, R. and Renelt, D. (1992) A sensitivity analysis of cross-country growth regressions, American Economic Review, 82, 942-963.

Lucas, R. E. (1988) On the mechanics of economic development, Journal of Monetary Economics, 22, 3-42.

Rahman, A. (1992) The informal financial sector in Bangladesh: An appraisal of its role in development, Development and Change, 23, 147-168. 
Romer, P. (1986) Increasing returns and long run growth, Journal of Political Economy 94, 1002-1037.

Sala-i-Martin, X. (1997) I just ran two million regressions, American Economic Review, 87, 178183.

Scully, G. W. (1995) The "growth tax" in the United States, Public Choice, 85, 71-80.

Scully, G. W. (1996) Taxation and economic growth in New Zealand, Pacific Economic Review, 1, 169-177.

SHAZAM (1997) SHAZAM Econometrics Computer Program, User's Reference Manual, Version 8.0, McGraw-Hill, New York.

Slemrod, J. (1985) An empirical test for tax evasion, Review of Economics and Statistics, LXVII, 232-238.

Taussig, F. W. (1925) Principles of Economics, Macmillan, New York (originally 1911).

Trandel, G. and Snow, A. (1999) Progressive income taxation and the underground economy, Economics Letters, 62, 217-222.

White, K. J. (1992) The Durbin-Watson test for autocorrelation in nonlinear models, Review of Economics and Statistics, LXXIV, 370-373. 


\section{FOOTNOTES}

1. Also, see Caragata and Small (1996) and Scully (1996b) for some related results.

2. See section 4.4 of Caragata (1998) for a detailed discussion of incentives and Aearned behaviour@n the present context.

3. See Giles (1997a, 1997b, 1997c, 1999a) for further details.

4. Recall, for example, the above discussion of the variables included in Giles' (1999b) model.

5. The inclusion or exclusion of this growth rate variable has only negligible effects on the results which are reported below.

6. These requirements are, in fact, fully supported by the results of some non-parametric analysis in progress by the first author and Betty Johnson.

7. There are few clear guidelines as to the choice of value for this parameter. We considered values between $l=0$ to $l=8$, and found the results to be quite insensitive to this choice.

8. Of course, that evidence relates only to measured economic activity.

9. Given the presence of cointegration, super-consistent estimates of the parameters will be obtained by (non-linear) least squares - or equivalently non-linear maximum likelihood estimation. This holds, regardless of which variable is chosen as the dependent variable for the fitted models. The relevant choice is clear, in economic terms, in our case.

10. Gerrard and Godfrey (1998) discuss the validity of regression diagnostics with nonstationary data.

11. In particular, note that in this figure, and in Figures 2(a) to 2(d), very smooth relationships emerge because real growth in GDP has been set to zero. 
Table 1

ADF \& KPSS Tests

for Unit Roots and Cointegration

(a) Unit Root Tests: ADF (KPSS)
$\mathrm{I}(2) v s . \mathbf{I}(1)$
I(1) vs. I(0)

$\begin{array}{lllllll}\text { Variable } & \mathbf{n} & \mathbf{p} & \mathbf{t} & \mathbf{n} & \mathbf{p} & \mathbf{t} \\ & (\mathbf{n}) & (\boldsymbol{l}) & \left(\boldsymbol{\eta}_{\tau}\right) & (\mathbf{n}) & (\boldsymbol{l}) & \left(\boldsymbol{\eta}_{\tau}\right) \\ (\mathbf{T} / \mathbf{G D P}) & 68 & 7 & -3.398 & 70 & 6 & -1.914 \\ & (76) & (0) & (0.062) & (77) & (0) & (1.656) \\ (\mathbf{H} / \mathbf{G D P}) & 23 & 2 & -3.444 & 24 & 2 & -2.700 \\ & (26) & (0) & (0.042) & (27) & (0) & (0.158) \\ \log (\mathbf{G D P R}) & 20 & 4 & -2.389 & 21 & 4 & 1.830 \\ & (25) & (0) & (0.038) & (26) & (0) & (0.133)\end{array}$

(b) Cointegration Tests: ADF (KPSS)

Drift/No Trend

n

(n)

27

(27)

\section{p}

(l)

0

(0) $\mathbf{t}$

$\left(\eta_{\mu}\right)$

$-3.430$

$(0.217)$ n

(n)

27

(27)
Drift \& Trend

$\mathbf{p} \quad \mathbf{t}$

(l) $\quad\left(\eta_{\tau}\right)$

$\begin{array}{ll}0 & -3.856 \\ (0) & (0.108)\end{array}$


Table 2

Maximum Likelihood Estimation Results

\section{Cum. Normal Logistic Gompertz Extreme Value}

$\begin{array}{lllll}\alpha & 1.4031 & 1.2665 & 0.0400 & 1.3342 \\ & (4.898) & (5.008) & (4.009) & (4.904) \\ \beta & 0.8126 & 0.4117 & & 0.4321 \\ & (3.796) & (3.759) & (4.119) & (3.736) \\ \gamma & 0.0872 & & & 0.0857 \\ & (1.218) & 0.0860 & 0.0885 & (1.176) \\ \mathbf{R}^{2} & 0.365 & (1.194) & (1.212) & 0.362 \\ \mathbf{D W} & 1.271 & & & 1.262 \\ & {[0.02]} & 1.264 & 0.368 & {[0.02]} \\ \text { GOF } & 3.589 & {[0.02]} & 1.278 & 2.617 \\ & \{0.17\} & 2.617 & {[0.02]} & \{0.27\}\end{array}$

Note: Asymptotic "t-values" appear in parentheses; exact "p-values" for the DW tests appear in brackets; and asymptotic "p-values" for the GOF tests appear in braces. 
Table 3

Tax Simulation Results

Cumulative Normal

$\%$ (T/GDP)

0

5

10

15

20

25

30

35

40

45

50

55

60

65

70

75

80

85

90

95

100
$\%$ (H/GDP) (std. error)

4.21

4.79

5.44

6.15

6.93

7.79

8.73

9.75

10.85

12.04

13.32

14.69

16.15

17.70

19.34

21.07

22.90

24.80

26.79

28.85

30.98

10.27
(1.02)

(0.95)

(0.86)

(0.74)

(0.59)

(0.41)

(0.26)

(0.33)

(0.61)

(0.99)

(1.43)

(1.93)

(2.48)

(3.08)

(3.74)

(4.45)

(5.20)

(5.99)

(6.81)

(7.67)

(8.54)

(0.51)
Logistic

$\%$ (H/GDP) (std. error)

4.41

(0.96)

4.95

(0.90)

5.56

$(0.83)$

6.23

$(0.72)$

6.98

$(0.58)$

7.81

8.73

$(0.26)$

9.75

$(0.33)$

10.87

(0.63)

12.10

(1.05)

13.45

(1.54)

14.93

(2.12)

16.54

(2.79)

18.28

(3.55)

20.17

22.19

24.36

(6.32)

26.68

(7.40)

29.11

(8.54)

31.67

(9.72)

34.36

(10.93)

10.26

(0.52) 
Table 3 (Continued)

Tax Simulation Results

\section{Gompertz}

\% (H/GDP) (std. error)

4.00

4.62

5.31

6.07

6.89

7.78

8.73

9.75

10.83

11.98

13.19

14.45

15.77

17.15

18.57

20.04

21.56

23.11

24.69

26.31

27.94

10.28
(1.08)

(1.01)

(0.90)

(0.77)

$(0.60)$

(0.41)

$(0.25)$

$(0.32)$

(0.59)

(0.94)

(1.32)

(1.74)

(2.20)

(2.67)

(3.17)

(3.69)

(4.22)

(4.76)

(5.31)

(5.86)

(6.41)

(0.51)
Extreme-value

$\%$ (H/GDP) (std. error)

4.46

$(0.95)$

4.99

(0.90)

5.59

$(0.82)$

6.25

$(0.71)$

6.99

$(0.57)$

7.81

8.73

(0.26)

9.74

10.87

(0.64)

12.12

(1.07)

13.50

(1.59)

15.03

(2.21)

16.71

18.56

(3.79)

20.58

(4.77)

22.80

25.21

27.83

(8.52)

30.66

(10.05)

33.70

(11.71)

36.96

(13.48)

10.26

(0.52) 
riyuie 1.

Tax Ratio and Hidden Economy Ratio

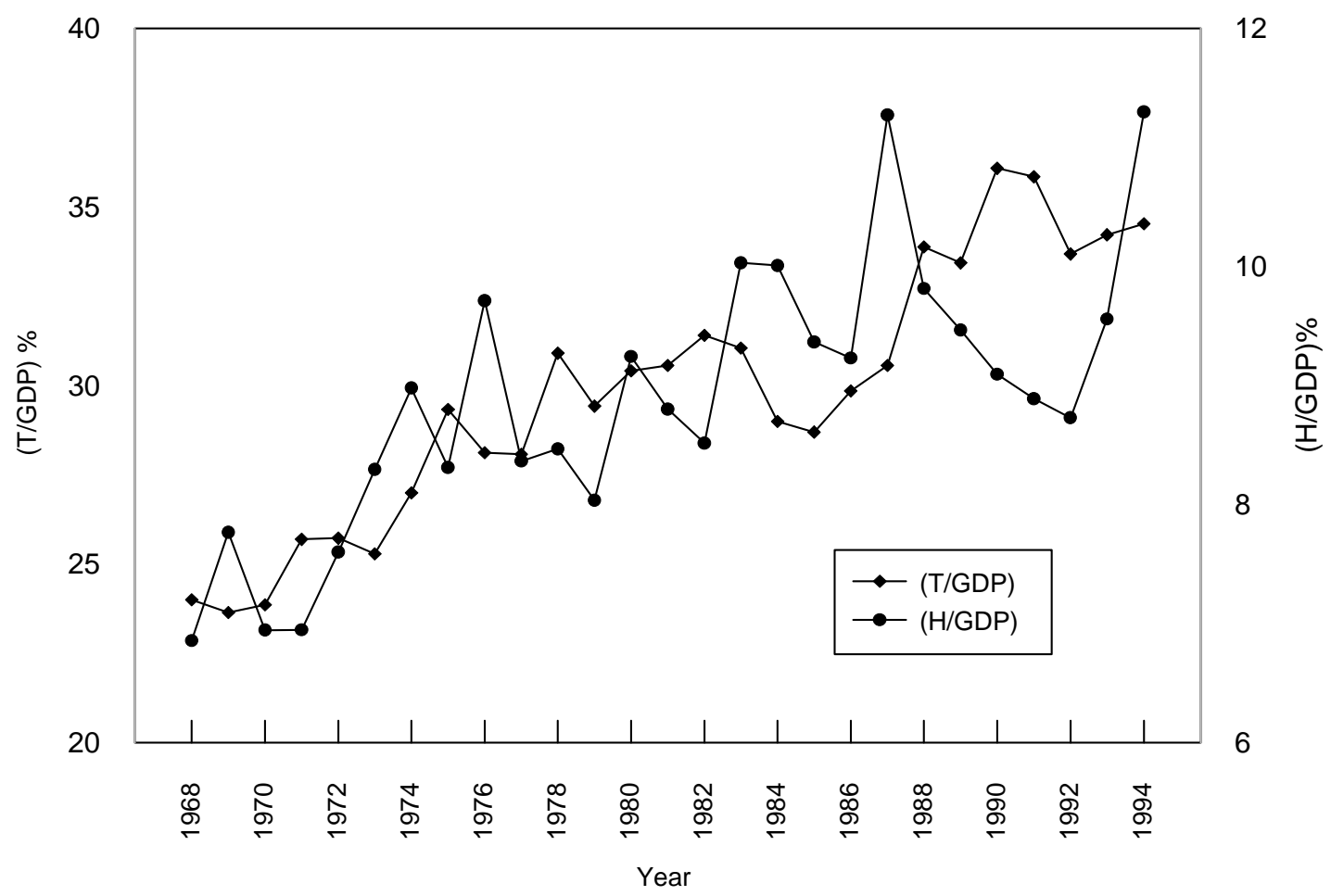


Partial Effect of (H/GDP) vs. (T/GDP)

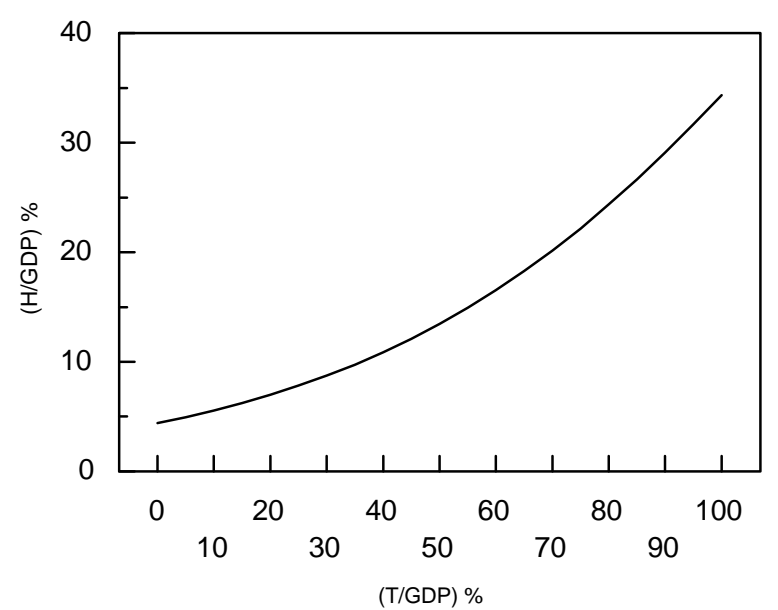

Figure 2(c) : Logistic Model Second Derivative of (H/GDP) w.r.t. (T/GDP)

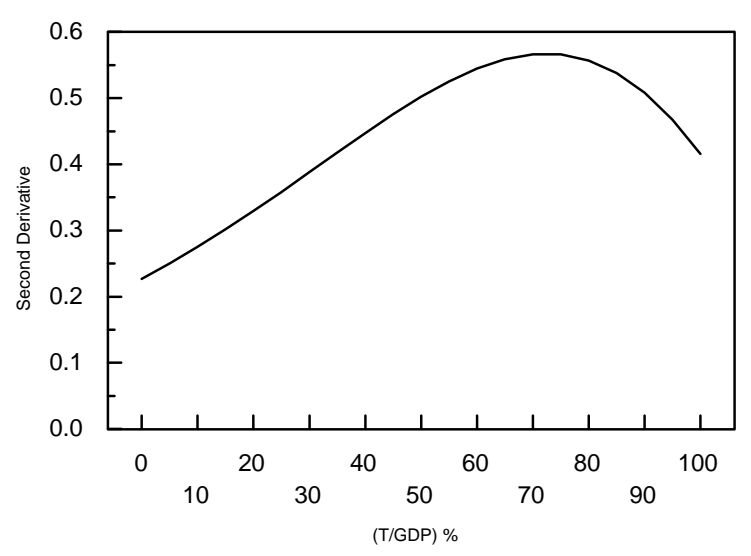

First Derivative of (H/GDP) w.r.t. (T/GDP)

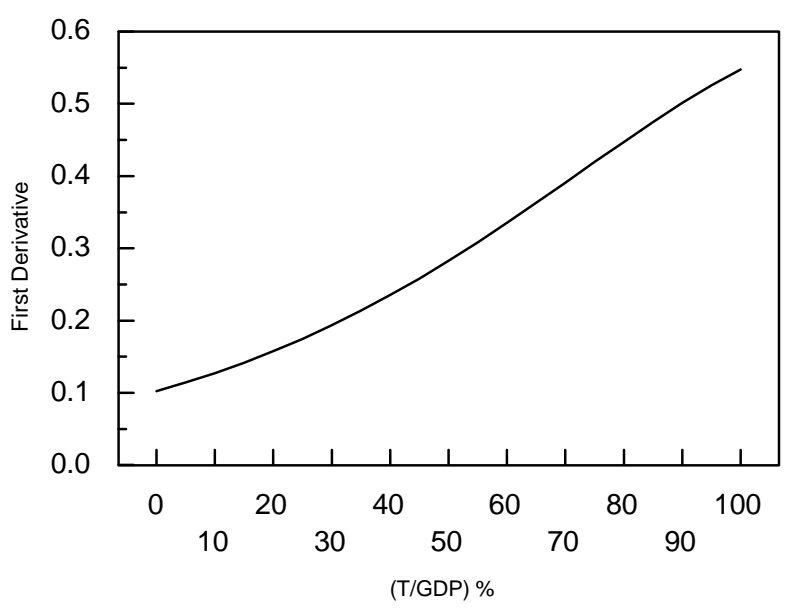

Figure 2(d) : Logistic Model Elasticity of (H/GDP) w.r.t. (T/GDP)

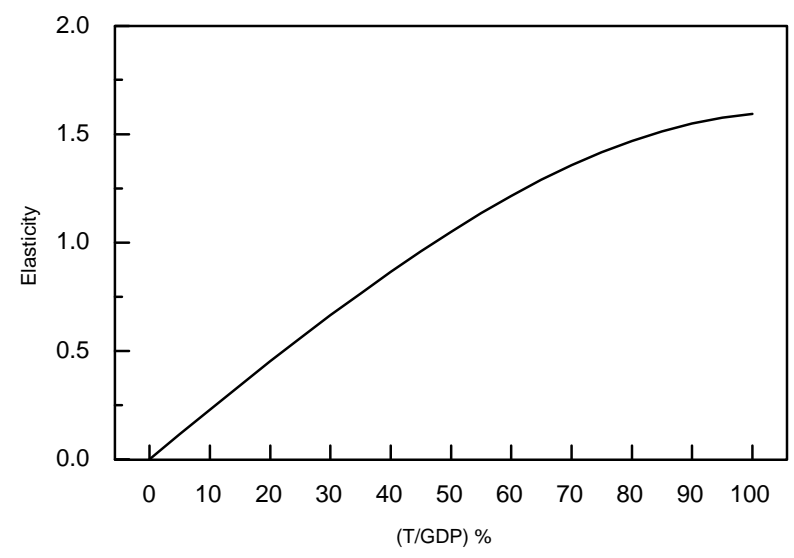

